\title{
Self-assembly and alignment of semiconductor nanoparticles on cellulose nanocrystals
}

\author{
Sonal Padalkar $\cdot$ Jeff R. Capadona $\cdot$ \\ Stuart J. Rowan - Christoph Weder · \\ Robert J. Moon · Lia A. Stanciu
}

\begin{abstract}
The synthesis of cadmium sulfide (CdS), zinc sulfide $(\mathrm{ZnS})$, and lead sulfide $(\mathrm{PbS})$ nanoparticle chains on cellulose nanocrystal (CNC) templates can be accomplished by the reaction of the precursor salts. The use of a cationic surfactant, cetyltrimethylammonium bromide (CTAB), was critical for the synthesis of well-defined semiconductor nanoparticle chains on the surface of the CNCs. The semiconductor nanoparticle particle size and packing density on CNC surface could be controlled by the variation of the precursor concentration and the $\mathrm{pH}$ of the salt solution.
\end{abstract}

\section{Introduction}

Fabrication of nanostructures such as nanowires, nanorods, nanotubes, and nanoparticles has attracted much attention in

S. Padalkar · R. J. Moon · L. A. Stanciu

School of Materials Engineering, Purdue University,

West Lafayette, IN 47907, USA

S. Padalkar $(\bowtie) \cdot$ R. J. Moon · L. A. Stanciu

Birck Nanotechnology Center, Purdue University,

West Lafayette, IN 47907, USA

e-mail: sonalpadalkar@gmail.com

\section{J. R. Capadona}

Rehabilitation Research and Development, Louis Stokes Cleveland DVA Medical Center, 10701 East Blvd., Cleveland, OH 44106, USA

J. R. Capadona · S. J. Rowan

Department of Biomedical Engineering, Case Western Reserve University, Cleveland, OH 44106, USA

J. R. Capadona $\cdot$ S. J. Rowan $\cdot$ C. Weder

Department of Macromolecular Science and Engineering, Case

Western Reserve University, Cleveland, OH 44106, USA the past decade due to the unique properties they exhibit. Their applicability ranges from optoelectronic devices to gas or biosensors [1-4]. Several approaches for the synthesis of these nanostructures have been explored. Biotemplating is one of the bottom-up techniques that employ biomolecules that exist in a wide range of nano-sized architectures. Thus, the ability to utilize such systems as templating agents offers the potential to access a range of synthetic nano-structures of similar dimensions. Among these, proteins, viruses, and DNA have been most widely investigated. However, they are often difficult to isolate in appreciable quantities and therefore expensive. Cellulose nanocrystals (CNC) are potentially an attractive alternative biotemplating material in the fabrication of nanostructures. CNCs have nanoscale size dimensions (5-20-nm diameter, 25-3000-nm long), a rod-like

\author{
S. J. Rowan · C. Weder \\ Department of Chemistry, Case Western Reserve University, \\ Cleveland, OH 44106, USA \\ C. Weder \\ Adolphe Merkle Institute and Fribourg Center \\ for Nanomaterials, University of Fribourg, \\ CH-1700 Fribourg, Switzerland

\section{R. J. Moon} \\ US Forest Service, Forest Products Laboratory, \\ Madison, WI 53726, USA
}


geometry and free hydroxyl groups exposed on its surface that can be chemically functionalized. Cellulose is abundantly available (extracted from trees, plants, tunicates, etc.) and is relatively inexpensive [5-7]. The use of such a template is promising since the dimensions, structure, and low production cost of the CNCs are favorable for the synthesis of nanoparticle chains or nanowires. The fabrication of nanowires via a biotemplated procedure open several avenues in applications where synthesis cost are required to be kept low. Along with this the nanowires can be placed in particular positions in nanocircuits which are generally difficult to access due to the complexity of the circuit design. There have been reports on the synthesis of metallic nanoparticles on cellulose, but the density of these nanoparticles has been extremely low [8-13]. Recently, we have successfully synthesized high density metallic nanoparticles (silver, gold, copper, and platinum) onto tunicate CNC surfaces [14]. The resulting metallic nanoparticle deposition led to a high surface coverage of individual CNCs. The nanoparticle size and density on the CNC surface could be controlled by varying the concentration of cetyltrimethylammonium bromide (CTAB), $\mathrm{pH}$ of the salt solutions, and the reduction time.

Along with metallic nanoparticles, semiconducting nanostructures are interesting materials due to the several unique properties they display. Semiconducting materials such as cadmium sulfide $(\mathrm{CdS})$, lead sulfide $(\mathrm{PbS})$, and zinc sulfide $(\mathrm{ZnS})$ have applications in solar cells, optoelectronic, and electronic devices [15-19]. CdS and ZnS are II-VI semiconducting materials with band gaps of 2.42 and $3.7 \mathrm{eV}$, respectively. The $\mathrm{CdS}$ band gap falls within the visible spectrum and can be used in the form of nanowires, nanotubes, and quantum dots for nonlinear optical devices, photovoltaic cells, and thin film transistors [19-21]. ZnS is a photoluminescent material and has field emission properties, with potential applications in light converting electrodes, ultraviolet light emitting diodes, or phosphors in cathode ray tubes [21-24].

DNA, viruses, and proteins have been extensively used as templates for the synthesis of $\mathrm{CdS}$ and $\mathrm{PbS}$ nanostructures [25-27], while to our knowledge, there are no reports in the literature on the fabrication of inorganic semiconductor materials as one-dimensional (1D) structures using CNC templates. There are some reports in the literature on the use of CNCs as templates for the growth of electrically (semi) conducting polymers [28-30].

In the current study, tunicate CNCs are used as biological templates for the synthesis of $\mathrm{CdS}, \mathrm{PbS}$, and $\mathrm{ZnS}$ nanostructures. The synthesis, characterization, and optimization of semiconducting nanoparticles precipitation on CNCs using a electroless deposition technique combined with a cationic surfactant CTAB are presented. Also, the role of the precursor concentration and the $\mathrm{pH}$ of the salt solution on nanoparticle synthesis are investigated.

\section{Experimental details}

\section{Formation of CNC template}

The CNCs were acquired from the mantels of tunicates. Thus, the CNCs were produced via acid hydrolysis (sulfuric acid) of the tunicate mantels according to a method reported in literature [6, 31, 32]. In brief, tunicates were placed in an aqueous solution of potassium hydroxide (3L, $5 \% \mathrm{w} / \mathrm{w}$ per $500 \mathrm{~g}$ of tunicate walls) and mechanically agitated at $80 \mathrm{C}$ for $24 \mathrm{~h}$. This step was repeated two times. The obtained cellulose was washed with water having a $\mathrm{pH}$ of 7.0. It was then treated with $10 \mathrm{~mL}$ of hypochlorite solution and $5 \mathrm{~mL}$ acetic acid. The resultant suspension was heated to $60{ }^{\circ} \mathrm{C}$. The suspension was then treated with hypochlorite solution and acetic acid repeatedly at $1 \mathrm{~h}$ time intervals until the white color cellulose was obtained. Finally, the cellulose was washed with water and converted into a pulp in a Waring blender. Hydrolysis of the cellulose pulp was carried out in sulfuric acid, to obtain sulfate-functionalized tunicate CNCs, where a cooled suspension of cellulose pulp in deionized water was treated with $98 \%$ sulfuric acid. The acid was added drop wise to the cellulose pulp with vigorous mechanical stirring. The dispersion was heated to $60{ }^{\circ} \mathrm{C}$ for $90 \mathrm{~min}$, followed by cooling to $0{ }^{\circ} \mathrm{C}$. It was then filtered and washed with deionized water. CNCs were well dispersible in water, which has been attributed to a small concentration of negatively charged sulfate groups on their surface left over from the acid hydrolysis extraction process [32]. The concentration of sulfate groups on CNC surfaces from sulfuric acid hydrolysis extraction processes has been reported as being very low and results in surface charge density of $\sim 84 \mathrm{mmol} \mathrm{kg}^{-1}$ [32].

Synthesis of semiconducting nanoparticles chains on CNCs

The fabrication of nanoparticles onto the surface of a biological template, often, use electroless deposition techniques on account of the simplicity of the procedure and mild reaction conditions [30]. The driving force for nanoparticles deposition relies on the difference between the redox potentials of the precursor salt to those of the biomolecule template structure. For the synthesis of $\mathrm{CdS}, \mathrm{PbS}$, and $\mathrm{ZnS}$ nanoparticle chains on CNC templates, the typical electroless deposition technique was used, with a small, but highly enabling modification. The precursors used were cadmium chloride $\left(\mathrm{CdCl}_{2}\right)$, lead nitrate $\left(\mathrm{Pb}\left(\mathrm{NO}_{3}\right)_{2}\right)$, zinc chloride $\left(\mathrm{ZnCl}_{2}\right)$ salt solutions, hydrogen sulfide gas $\left(\mathrm{H}_{2} \mathrm{~S}\right)$, and the CTAB surfactant. All the chemicals were purchased from Sigma-Aldrich and were used as obtained without any purification or any processing. The salt solution precursors 
were used as the source of cadmium $(\mathrm{Cd})$, lead $(\mathrm{Pb})$, and zinc $(\mathrm{Zn})$, respectively, while the $\mathrm{H}_{2} \mathrm{~S}$ gas was used as the sulfur source. In a typical example, an original solution of CNCs ( $\sim 2 \mathrm{wt} \%$ at $\mathrm{pH} \sim 2)$ was diluted by the addition of distilled water $(100 \mu \mathrm{L}$ of $2 \mathrm{wt} \% \mathrm{CNC}$ in $10 \mathrm{~mL}$ distilled water, $\mathrm{pH} \sim 6$ ), placed on a transmission electron microscope (TEM) grid (carbon-coated copper grid, 3-mm diameter), and used as a substrate for the deposition of semiconductor nanoparticles. The dilution was carried out to avoid a mat-like structure on the substrate due to high concentration of CNCs. In the next *step, an aqueous solution of the surfactant CTAB $(0.5 \mathrm{mM}, 3 \mu \mathrm{L})$ was added to the droplet of the CNC dispersion, and the mixture was incubated at room temperature for $5 \mathrm{~min}$. This was followed by the addition of a given precursor salt solution $(3 \mu \mathrm{L})$, $\mathrm{CdCl}_{2} \quad(0.8 \mathrm{mM}), \quad \mathrm{Pb}\left(\mathrm{NO}_{3}\right)_{2} \quad(0.5 \mathrm{mM}), \quad$ and $\quad \mathrm{ZnCl}_{2}$ $(2.0 \mathrm{mM})$, at a set $\mathrm{pH}$ (4 or 7), and the resulting mixture was allowed to react at room temperature for another $5 \mathrm{~min}$. Next, $\mathrm{H}_{2} \mathrm{~S}$ gas was passed over the substrate for $2 \mathrm{~min}$. The TEM grid substrate was then washed with distilled water and dried in air. The washing process was carried out by placing a drop of deionized water on a piece of parafilm followed by immersing the sample in this droplet for $5 \mathrm{~min}$. The sample was dried by removing the excess water with a blotting paper and leaving the sample in air.

\section{Characterization of $\mathrm{CNC}$ and semiconducting nanoparticle chains}

The CNC morphology and the resulting semiconducting particles were characterized with a Philips CM-10 TEM, operating at $80 \mathrm{kV}$. A carbon-coated copper TEM grid was used as a substrate. The $\mathrm{CNC}$ suspension in distilled water $(3 \mu \mathrm{L})$ was pipette out on to the TEM grid. It was then stained using $2 \%$ uranyl acetate solution for $1 \mathrm{~min}$. The excess solution from the substrate was removed with a blotting paper. The grid was dried, loaded in the specimen holder, and imaged under the TEM microscope.

High resolution transmission electron microscopy (HRTEM) images were obtained to study the crystalline nature of the semiconducting nanoparticles chains. HRTEM images were recorded on a FEI Titan 80/300 TEM operating at $300 \mathrm{kV}$. The electron energy loss (EELS) spectra were obtained with the same equipment, and used to confirm the chemical composition of $\mathrm{CdS}, \mathrm{PbS}$, and $\mathrm{ZnS}$ nanostructures. A similar sample preparation was used as described above.

\section{Results and discussion}

The diameter and morphology of the CNC template were studied by TEM imaging. Figure 1 shows that the diameter

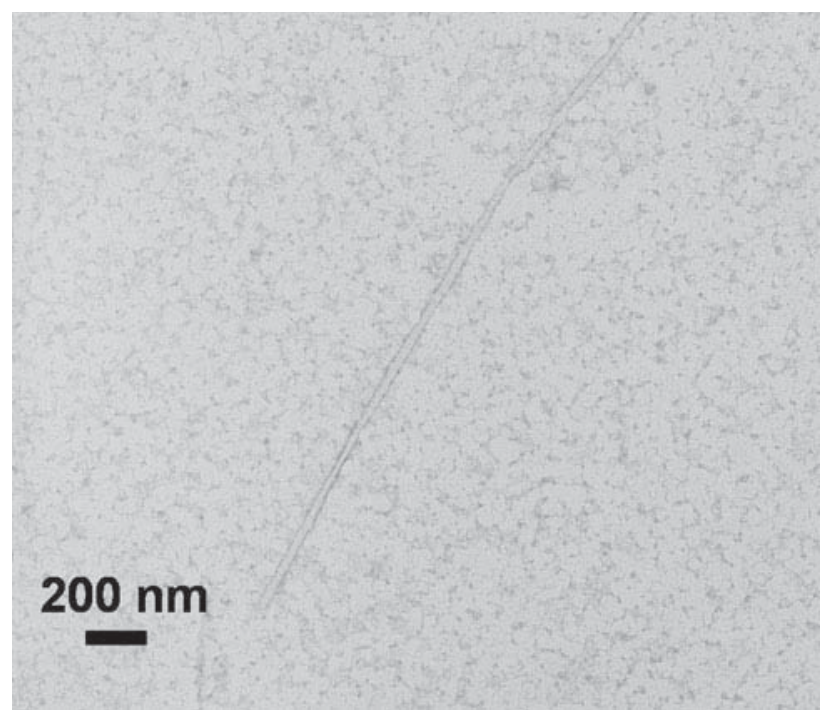

Fig. 1 TEM image of a CNC template

was $\sim 10-20 \mathrm{~nm}$ and the length was between $100 \mathrm{~nm}$ to several microns. This was consistent with other reports in the literature $[5,7]$.

The fabrication of semiconducting nanoparticles onto the surface of a biological template displaying negative charges on their surface, such as DNA, viruses, or fibrillar proteins, can be achieved by the popular electroless deposition technique, which is often used due to its simplicity and mild synthetic conditions. However, this method is not easily applicable to polysaccharides, such as CNCs, which possess mostly neutral hydroxyl groups, as they may not readily interact with the cations during the initial electrostatic interaction step in the synthesis process. Due to the limited availability of negatively charged groups on CNCs, this approach registered very limited success in our initial attempts to use CNCs as templates for semiconductor nanostructures synthesis. Except for a small negative charge given by the sulfate groups, CNC surfaces display mostly neutral hydroxyl groups (see Sect. Formation of CNC template). Considering this, we can speculate that the small amounts of negative charges and the neutral $\mathrm{OH}$ groups did not sufficiently interact with cations to cause the precipitation of semiconducting nanoparticles in sufficient amounts to ensure complete coverage of the CNCs just via deposition of salts, with no CTAB. To illustrate this, Fig. 2a shows that, in the absence of CTAB, $\mathrm{CdS}$ nanoparticles were deposited on the substrate rather than on the CNCs. In contrast, the TEM results reveal that after the inclusion of the cationic surfactant, $\mathrm{CTAB}$, into the reaction process, semiconducting nanostructures were formed preferentially on $\mathrm{CNC}$ surface. Figure $2 \mathrm{~b}$ shows $a$ striking difference when compared with Fig. 2a. Figure $2 b$ shows that in the presence of CTAB, the semiconducting nanoparticles $(\mathrm{CdS})$ were stabilized on the $\mathrm{CNC}$ surface in 

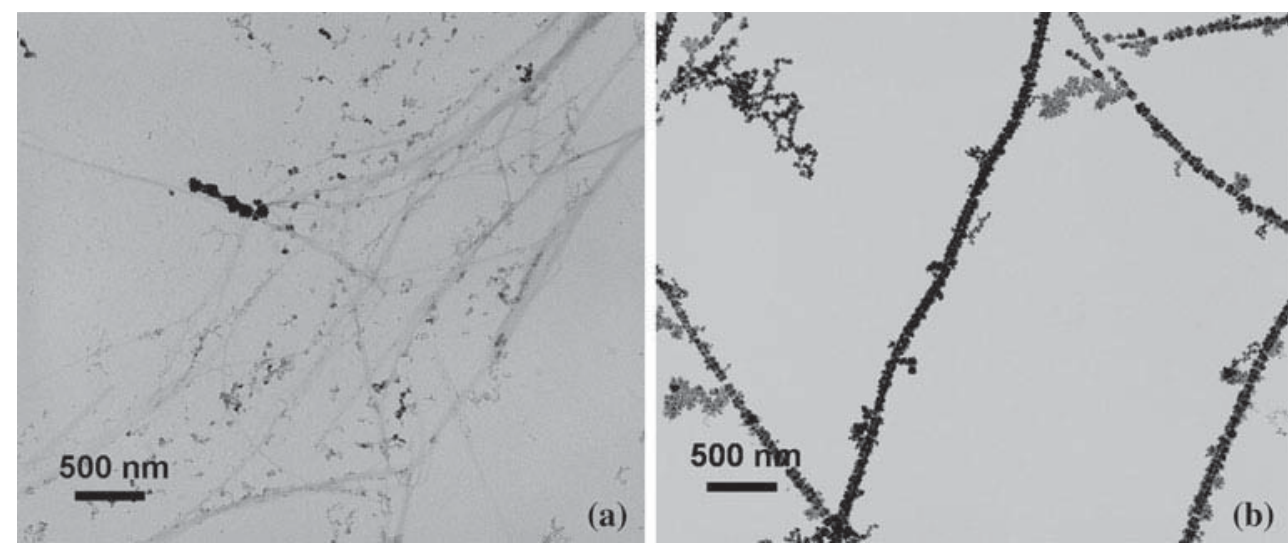

Fig. 2 TEM images of CdS nanoparticle samples in the absence (a) and presence of (b) CTAB

a virtually continuous chain. The average particles size, as measured by TEM, was approximately $55 \mathrm{~nm}$. The sample was prepared with a precursor concentration of $0.8 \mathrm{mM}$ $\left(\mathrm{CdCl}_{2}\right), \mathrm{H}_{2} \mathrm{~S}$ exposure time of $2 \mathrm{~min}$, and a neutral $\mathrm{pH}$ of the salt solution.

To further emphasize the significance of CTAB in the synthesis process, experiments were performed where $\mathrm{CdS}$ nanoparticles were synthesized without the presence of $\mathrm{CNC}$ templates, under the same experimental conditions used for the results in Fig. $2\left(0.8 \mathrm{mM} \mathrm{CdCl}_{2}, 2 \operatorname{min~}_{2} \mathrm{~S}\right.$ exposure time, and neutral $\mathrm{pH}$ of the salt solution). When CTAB was used in the synthesis of these CNC-free nanoparticles, the CdS nanoparticles appear to form either as individual nanoparticles or in small agglomerates (Fig. 3a). In contrast, when these exact same experiments were performed without $\mathrm{CTAB}$, there was significant agglomeration of the CdS nanoparticles (Fig. 3b).

CTAB is a cationic surfactant that, like other surfactants, forms micelles above the critical micelle concentration (CMC). We propose that $\mathrm{CTAB}$ acts as a nanoparticle stabilizer inside its micellar core, a role previously reported in literature, but the exact mechanism of the stabilization process is not completely understood [20,21]. The CMC of CTAB is $1.0 \mathrm{mM}$ [33]. Below CMC, CTAB forms individual micelles, while above this concentration the $\mathrm{CTAB}$ micelles self-associate into nanorod-like structures. When this occurs, the effective concentration of free CTAB micelles available for capping semiconducting nanoparticles decreases, which in turn leads to a decrease of CTABstabilized nanoparticles available to deposit on the CNCs. In our previous study [14], we reported the synthesis of single element (metallic) nanoparticles at different $\mathrm{CTAB}$ concentrations. The concentration of $\mathrm{CTAB}$ was varied from 0.1 to $1.0 \mathrm{mM}$, and it was observed that the nanoparticle coverage increased gradually from 0.1 to $0.5 \mathrm{mM}$ $\mathrm{CTAB}$ and then decreased for $1.0 \mathrm{mM}$ of CTAB. Based on the $\mathrm{CMC}$ value of $1 \mathrm{mM}$ for $\mathrm{CTAB}$, and our previous experimental observations, a concentration of $0.5 \mathrm{mM}$ was chosen for this study.

In this case, we propose that $\mathrm{CdS}, \mathrm{PbS}$, and $\mathrm{ZnS}$ nanoparticles are formed via the chemical reaction between precursor salts and $\mathrm{H}_{2} \mathrm{~S}$, and $\mathrm{CTAB}$ might act as a stabilizer, forming small agglomerates as shown in Fig. 3a. The nanoparticle-CTAB assemblies are non-covalently attached to the hydrophilic hydroxyl groups that cover the surface of the CNCs. The CNC structure acts like a template, resulting in semiconducting nanoparticle chains or nanowire-like assemblies. Here, we can make again the observation that the CNCs should display some level of negative surface charge coming from the residual sulfate groups introduced through acid hydrolysis. However, our experimental results (Fig. 2a) show that this charge is insufficient to strongly react with the metallic cations. From these results, it appears that when CTAB is not used as a stabilizer and link to the CNCs, solely the interaction of $\mathrm{Cd}^{2+}$ with the negative charges results in non-specific CdS deposition. These considerations are a starting point, but it is difficult, if not impossible, based on the current experimental data, to pinpoint with a high level of confidence, the exact mechanism that explains why the deposition of semiconducting nanoparticles becomes so specific and directed in the presence of CTAB. It is however safe to assume that, at least to some extent, the CTAB forming individual micelles that interact with the neutral $\mathrm{OH}$ groups of $\mathrm{CNCs}$ plays a major role in this link of chemical events.

The characterization of these semiconducting nanostructures using EELS confirmed the chemical composition of the $\mathrm{CdS}, \mathrm{PbS}$, and $\mathrm{ZnS}$ nanoparticles formed on the CNCs. Figure 4 shows the EELS spectra for CdS and PbS samples. For the CdS sample, the EELS spectra show the cadmium $\mathrm{M}_{4,5}$ edge at $404 \mathrm{eV}$ and the sulfur $\mathrm{L}_{2,3}$ edge at $165 \mathrm{eV}$. Likewise, for $\mathrm{PbS}$, the lead $\mathrm{O}_{2,3}$ edge at $86 \mathrm{eV}$ and sulfur $\mathrm{L}_{2,3}$ edge at $165 \mathrm{eV}$. For the $\mathrm{ZnS}$ sample, the EELS spectra showed the zinc $\mathrm{L}_{3}, \mathrm{~L}_{2}$, and $\mathrm{L}_{1}$ edges at 1020,1043 , 

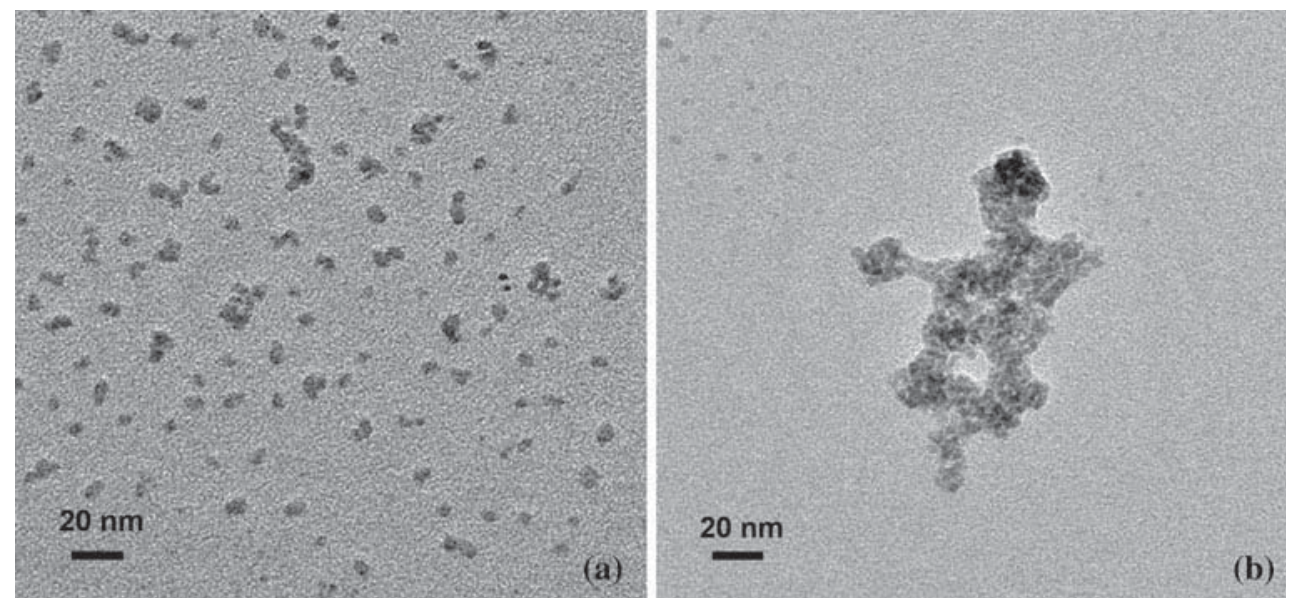

Fig. 3 TEM images of CdS nanoparticle samples with (a) and without (b) CTAB, in the absence of the CNC template

Fig. 4 EELS spectra. CdS sample showing the a cadmium $\mathrm{M}_{4,5}$ edge at $404 \mathrm{eV}$ and the b sulfur $\mathrm{L}_{2,3}$ edge at $165 \mathrm{eV}$. $\mathrm{PbS}$ sample showing the $\mathbf{c}$ lead $\mathrm{O}_{2,3}$ edge at $86 \mathrm{eV}$ and the d sulfur $\mathrm{L}_{2,3}$ edge at $165 \mathrm{eV}$. The spectra also show the carbon $\mathrm{K}$ edge at $300 \mathrm{eV}$, likely resulting of the carbon TEM grid
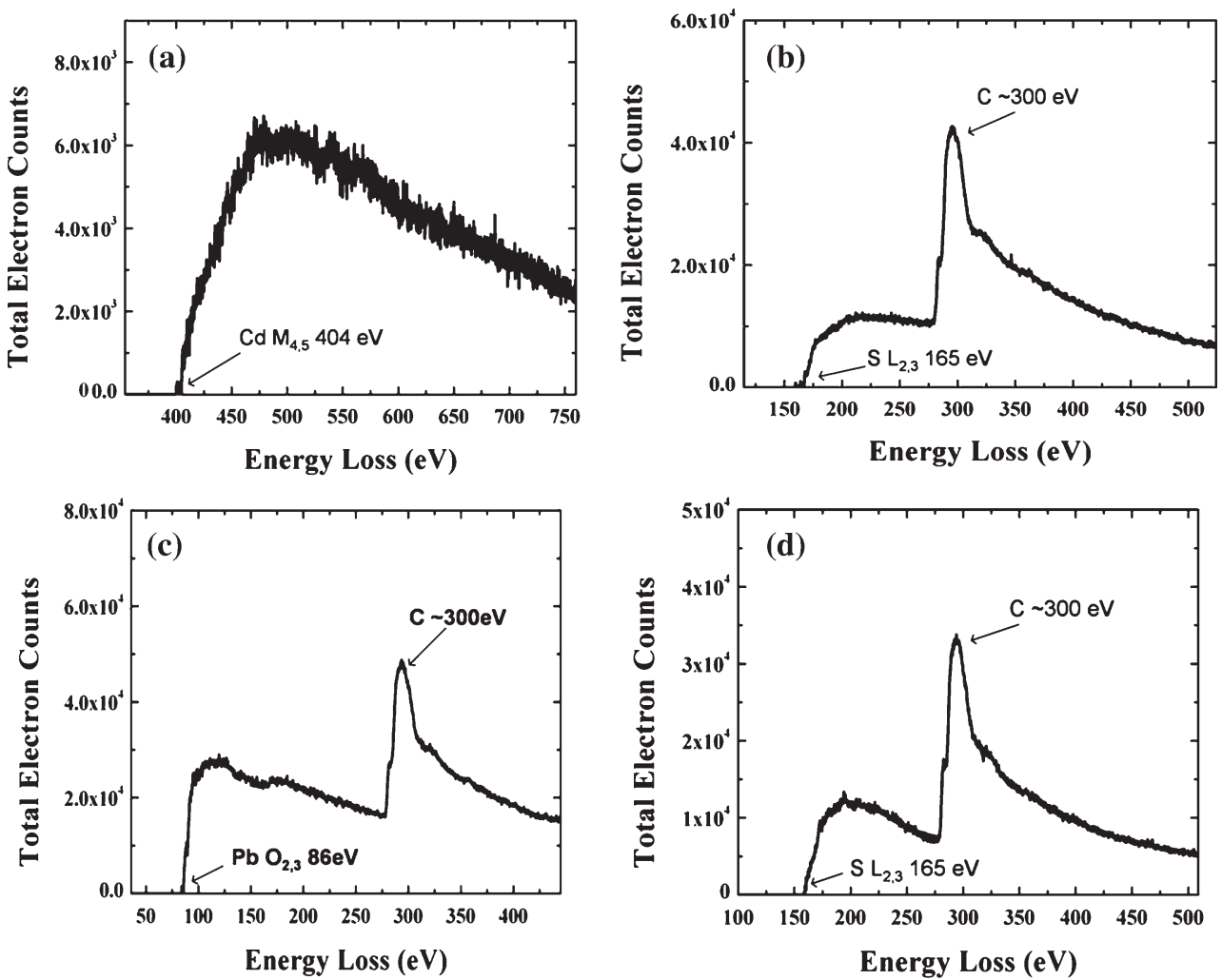

and $1194 \mathrm{eV}$, respectively, and the sulfur $\mathrm{L}_{2,3}$ edge at $165 \mathrm{eV}$ (not shown here). The spectra also show the Carbon $\mathrm{K}$ edge at $300 \mathrm{eV}$, contributed from the carbon coating of the TEM grid.

High resolution TEM imaging was carried out to study the nanocrystalline nature of the semiconducting nanostructures. Figure 5 shows HRTEM images of $\mathrm{CdS}, \mathrm{PbS}$, and $\mathrm{ZnS}$ nanoparticles on CNCs. In general, the $\mathrm{CdS}$ and $\mathrm{ZnS}$ nanoparticles ( $\sim 55 \mathrm{~nm}$ in diameter) assembled on the surface of the CNCs were agglomerates of much smaller nanoparticles. HRTEM images of $\mathrm{CdS}$ and $\mathrm{ZnS}$ nanoparticles confirmed that the agglomerates consist of several nanocrystals with sizes ranging between 2 and $6 \mathrm{~nm}$ (Fig. 2). By contrast, the $\mathrm{PbS}$ particles produced were identified as single crystals with a cubic morphology, as evident from the lattice fringes present in the HRTEM images.

To maximize the coverage of the semiconductor nanoparticles on the $\mathrm{CNCs}$, two process parameters $(\mathrm{pH}$ of salt solution and $\mathrm{H}_{2} \mathrm{~S}$ exposure time) were 

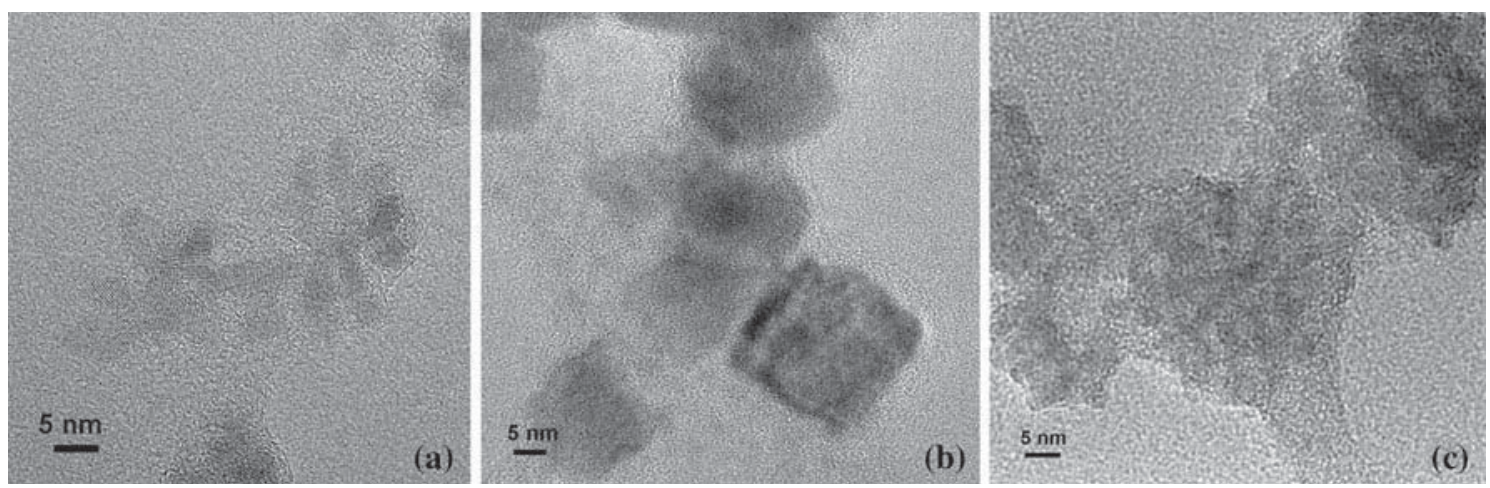

Fig. 5 HRTEM images from the $\mathrm{CdS}(\mathbf{a}), \mathrm{PbS}(\mathbf{b})$, and $\mathrm{ZnS}(\mathbf{c})$ samples. The semiconducting nanoparticles are made up of several nanocrystals in the case of $\mathrm{CdS}$ and $\mathrm{ZnS}$. The PbS sample shows cubic morphology of the nanoparticles

systematically varied to assess their role in resulting nanoparticle formation on the CNC surface. First, the influence of the $\mathrm{pH}$ of the precursor solution on the particle size and morphology was investigated for $\mathrm{CdS}, \mathrm{PbS}$, and $\mathrm{ZnS}$ nanoparticles via TEM imaging. The $\mathrm{CdCl}_{2}$, $\mathrm{Pb}\left(\mathrm{NO}_{3}\right)_{2}$, and $\mathrm{ZnCl}_{2}$ concentration was $0.8,0.5$, and $2 \mathrm{mM}$, respectively. The reaction time was kept constant at $5 \mathrm{~min}$, and the results obtained at two values of the $\mathrm{pH}$ of the salt solutions, $\mathrm{pH}=4$ and $\mathrm{pH}=7$, were compared. To obtain an acidic salt solution, $\mathrm{HCl}$ was added, while $\mathrm{NH}_{4} \mathrm{OH}$ was added to increase the $\mathrm{pH}$ value. The $\mathrm{pH}$ of the salt solution was measured using a $\mathrm{pH}$ meter before the synthesis. It was observed that both the particle size and the density of nanoparticles on the CNC surface increased as the $\mathrm{pH}$ of the salt solution increased, as shown in Fig. 6. Here, only the results obtained from the CdS samples are shown. Similar trends were observed for the $\mathrm{PbS}$ and $\mathrm{ZnS}$ samples. The observations can be explained with the help of the following reactions occurring during the synthesis process. An acidic medium will lead to the following reaction mechanism:

$$
\mathrm{H}_{2} \mathrm{~S}+\mathrm{H}_{2} \mathrm{O}=\mathrm{S}^{2-}+\mathrm{HS}^{-}+2 \mathrm{H}^{+}+\mathrm{OH}^{-}
$$$$
\mathrm{S}^{2-}+\mathrm{H}^{+}=\mathrm{HS}^{-}
$$

As the $\mathrm{pH}$ increases by the addition of $\mathrm{NH}_{4} \mathrm{OH}$, more hydroxyl ions are introduced in the reaction, and the following reaction becomes valid:

$$
\mathrm{HS}^{-}+\mathrm{OH}^{-}=\mathrm{S}^{2-}+\mathrm{H}_{2} \mathrm{O}
$$

From the above equations it can be inferred that as the $\mathrm{pH}$ of the medium increases, more $\mathrm{S}^{2-}$ anions are available to combine with the cations such as $\mathrm{Cd}^{2+}$ increasing the nucleation and growth rates. An important observation here relates again to the fact that the $\mathrm{CNCs}$ have an inherent surface charge. Since our $\mathrm{pH}$ is generally kept at an acidic (4) or neutral (7) value, and our experimental results showed that few nanoparticles were deposited on CNCs in the absence of CTAB (Fig. 2a), we speculate that these negative charges were either neutralized by the protons present in solution due to the fairly acidic medium, or by the $\mathrm{Cd}^{2+}$ or $\mathrm{Pb}^{2+}$ cations that are free in solution. We believe that the few nanoparticles deposited on the $\mathrm{CNC}$
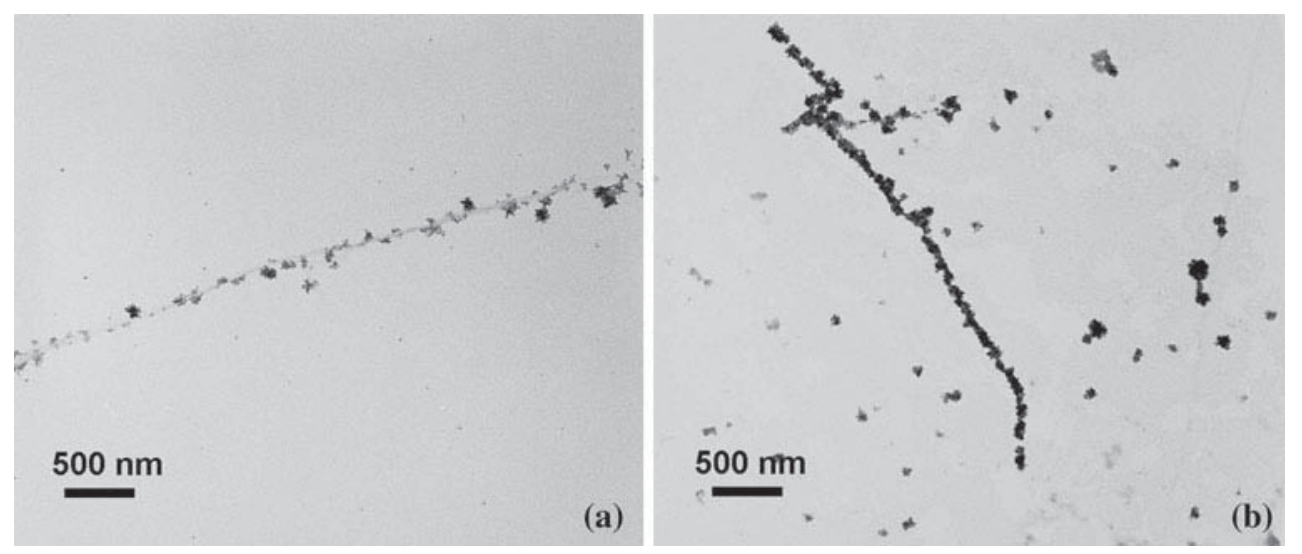

Fig. 6 TEM images of CdS samples with varying $\mathrm{pH}$ of the salt solution from 4 (a) to 7 (b) 
surface in the absence of CTAB are there precisely due to these residual negative charges on the CNC surface.

The next set of experiments was carried out with the objective of varying the particles size and varying the coverage of the CNC template by just changing the $\mathrm{H}_{2} \mathrm{~S}$ exposure time, while keeping all the other reaction parameters the same as in the previously described experiments. For this set of experiments, the exposure time was varied from 2, 5 to $10 \mathrm{~min}$. The TEM images in Figs. 7, 8, and 9 show the evolution of the particle size with changing exposure time. From these TEM images, it can be clearly seen that the particle size increases with an increase in $\mathrm{H}_{2} \mathrm{~S}$ exposure time. The cubic nature of the $\mathrm{PbS}$ nanoparticles (Fig. 8) is due to the rocksalt cubic structure of PbS. The
HRTEM images of these PbS samples (Fig. 5) also reveal that each cube is a single crystal, where uniform lattice fringes were seen. The morphology of $\mathrm{CdS}$ and $\mathrm{ZnS}$ nanoparticles appear more like agglomerates and are composed of several small nanocrystals as seen in the HRTEM images. From the TEM images in Fig. 7, 8, and 9, it is clear that nanoparticles of different architectures can also be synthesized via this fabrication procedure. These experiments indicate that the nanoparticle size can be varied independently by varying the $\mathrm{pH}$ of the salt of solution and the $\mathrm{H}_{2} \mathrm{~S}$ exposure time. Moreover, the coverage of the template also could be greatly improved by varying the process parameters, helping in the formation of nanowire-like structures.
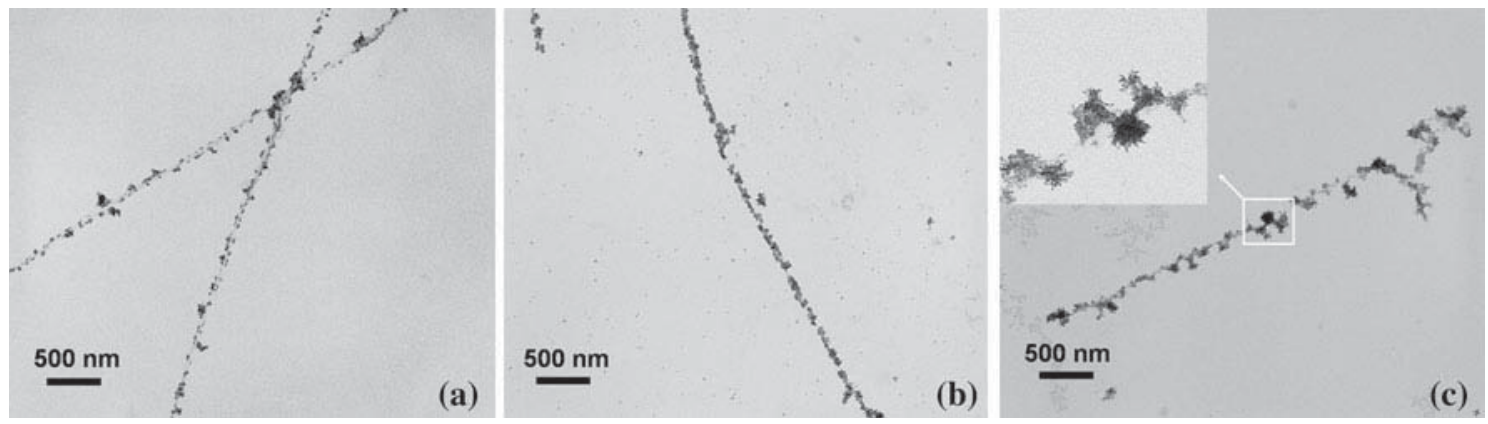

Fig. 7 TEM images of CdS samples with varying $\mathrm{H}_{2} \mathrm{~S}$ exposure time of 2 min (a), 5 min (b), and 10 min (c)
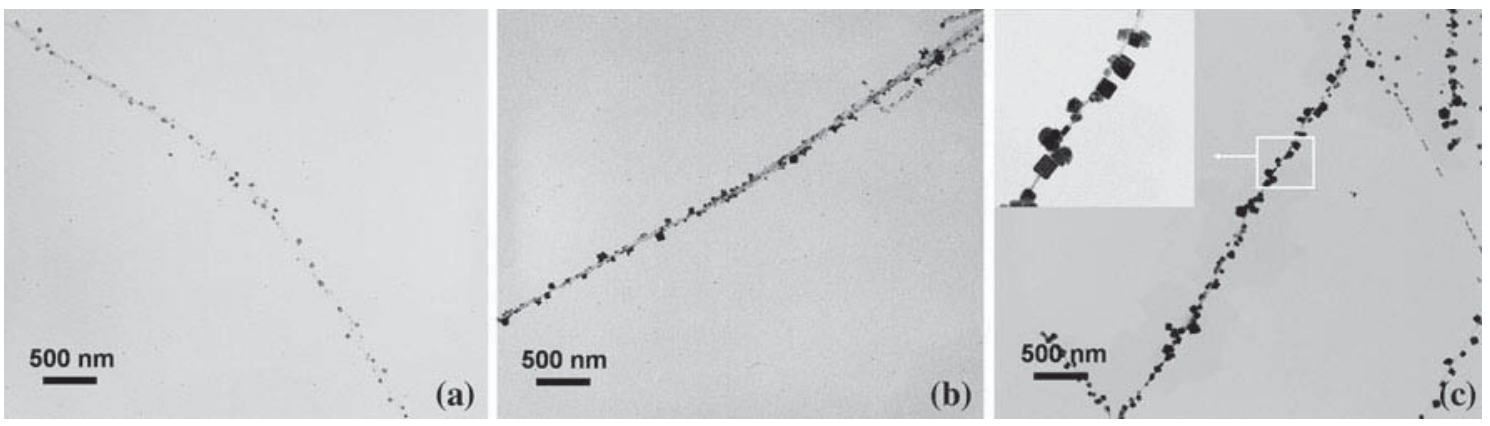

Fig. $8 \mathrm{TEM}$ images of $\mathrm{PbS}$ samples with varying $\mathrm{H}_{2} \mathrm{~S}$ exposure time of $2 \mathrm{~min}(\mathbf{a}), 5 \mathrm{~min}(\mathbf{b})$, and $10 \mathrm{~min}$ (c)
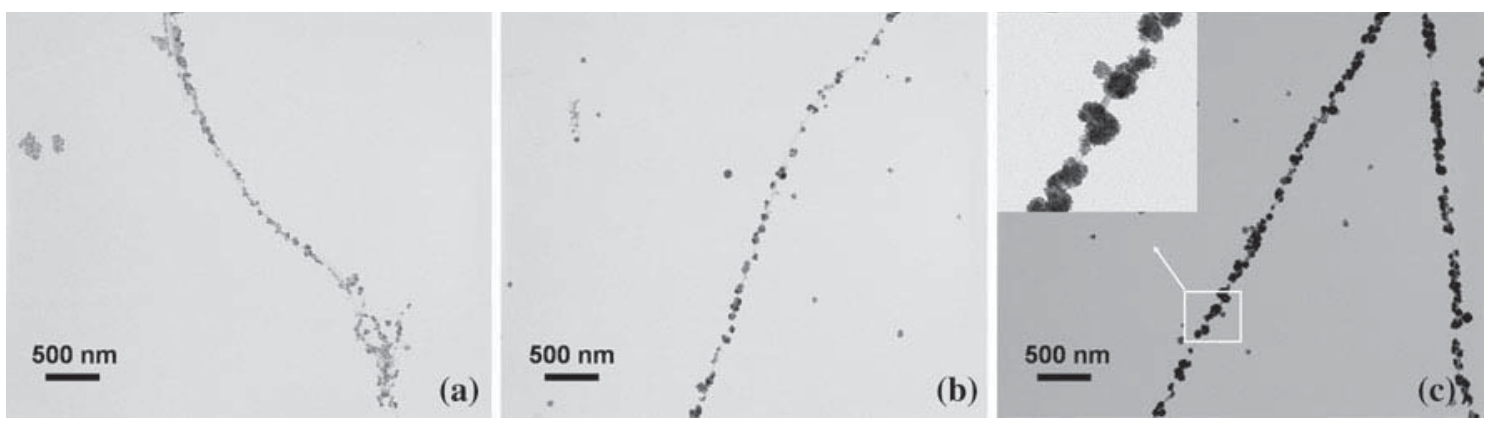

Fig. 9 TEM images of $\mathrm{ZnS}$ samples with varying $\mathrm{H}_{2} \mathrm{~S}$ exposure time of $2 \mathrm{~min}(\mathbf{a}), 5 \mathrm{~min}$ (b), and $10 \mathrm{~min}$ (c) 


\section{Conclusions}

In summary, we demonstrated that CNCs can be coupled with the stabilizing properties of surfactants and exploited for the fabrication of nanoarchitectures of various semiconducting materials such as $\mathrm{CdS}, \mathrm{ZnS}$, and $\mathrm{PbS}$. The results indicate that the same platform could be extended to serve as an alternative universal platform for engineering a variety of functional materials at the nanoscale. This universal platform could present advantages over DNA or protein templating in terms of costs, simplicity, and versatility and as such offers advantages for translating the fabrication of functional nanomaterials into real life electronic and optical nanodevices.

Acknowledgements The authors are grateful for the financial support provided by the US Forest Services and NSF DMR\#0804874. Christoph Weder acknowledges support from the Adolphe Merkle Foundation.

\section{References:}

1. Cui Y, Lieber CM (2001) Science 291:851

2. Duan XF, Huang Y, Cui Y, Wang JF, Lieber CM (2001) Nature 409:66

3. Huang Y, Duan XF, Cui Y, Lauhon LJ, Kim KH, Lieber CM (2001) Science 294:1313

4. Duan XF, Huang Y, Agarwal R, Lieber CM (2003) Nature 421:241. doi:10.1038/Nature01353

5. Habibi Y, Lucia LA, Rojas OJ (2010) Chem Rev 110:3479. doi:10.1021/cr900339w

6. Eichhorn SJ, Dufresne A, Aranguren M et al (2010) J Mater Sci 45:1. doi:10.1007/s10853-009-3874-0

7. Masa S, Alloin F, Dufresne A (2005) Biomacromolecules 6:612. doi:10.1021/Bm0493685

8. Son WK, Youk JH, Park WH (2006) Carbohydr Polym 65:430

9. Shin Y, Bae IT, Arey BW, Exarhos GJ (2008) J Phys Chem C 112:4844

10. Shin Y, Bae IT, Arey BW, Exarhos GJ (2007) Mater Lett 61:3215
11. Cai J, Kimura S, Wada M, Kuga S (2009) Biomacromolecules 10:87

12. He JH, Kunitake T, Nakao A (2003) Chem Mater 15:4401

13. Maneerung T, Tokura S, Rujiravanit R (2008) Carbohydr Polym $72: 43$

14. Padalkar S, Capadona JR, Rowan SJ, Weder C, Won YH, Moon R, Stanciu L (2010) Langmuir 26:8497. doi:10.1021/la904439p

15. Horne WS, Stout CD, Ghadiri MR (2003) J Am Chem Soc 125:9372. doi:10.1021/Ja034358h

16. Serio TR, Cashikar AG, Kowal AS et al (2000) Science 289:1317

17. Scheibel T, Lindquist SL (2001) Nat Struct Biol 8:958

18. DePace AH, Weissman JS (2002) Nat Struct Biol 9:389. doi:10.1038/Nsb786

19. Ma RM, Dai L, Huo HB et al (2006) Appl Phys Lett 89:203120. doi:10.1063/1.2387982

20. Milliron DJ, Hughes SM, Cui Y et al (2004) Nature 430:190. doi:10.1038/Nature02695

21. Borchert H, Dorfs D, McGinley C et al (2003) J Phys Chem B 107:7486. doi:10.1021/Jp027485t

22. Zhang DB, Qi LM, Cheng HM, Ma JM (2002) J Colloid Interface Sci 246:413. doi:10.1006/jcis.2001.8081

23. Yin LW, Bando Y, Zhan JH, Li MS, Golberg D (2005) Adv Mater 17:1972. doi:10.1002/adma.200401839

24. Ma C, Moore D, Li J, Wang ZL (2003) Adv Mater 15:228

25. Dong LQ, Hollis T, Connolly BA, Wright NG, Horrocks BR, Houlton A (2007) Adv Mater 19:1748. doi:10.1002/adma.20060 2543

26. Mao CB, Solis DJ, Reiss BD et al (2004) Science 303:213

27. Huang Y, Chiang CY, Lee SK et al (2005) Nano Lett 5:1429. doi:10.1021/N1050795d

28. van den Berg O, Schroeter M, Capadona JR, Weder C (2007) J Mater Chem 17:2746. doi:10.1039/B700878c

29. Mendez JD, Weder C (2010) Polym Chem 1:1237. doi:10.1039/ c0py00118j

30. Padalkar S, Hulleman JD, Kim SM, Rochet JC, Stach EA, Stanciu LA (2008) Nanotechnology 19:275602. doi:10.1088/ 0957-4484/19/27/275602

31. van den Berg O, Capadona JR, Weder C (2007) Biomacromolecules 8:1353. doi:10.1021/Bm061104q

32. Araki J, Wada M, Kuga S, Okano T (1998) Colloids Surf A Physicochem Eng Asp 142:75

33. Wang Z, Liu J, Chen X, Wan J, Qian Y (2005) Chem Eur J $11: 160$ 